\title{
Genetic and Epigenetic Control of Puberty
}

\author{
María Carolina Manotas ${ }^{a}$ Daniel Mauricio González ${ }^{a}$ Camila Céspedes $^{b, c}$ \\ Catalina Forero $^{b, c}$ Adriana Patricia Rojas Moreno ${ }^{a}$ \\ anstitute of Human Genetics, Faculty of Medicine, Pontificia Universidad Javeriana, Bogotá, Colombia; \\ bPediatric Endocrinologist, Hospital Universitario San Ignacio, Bogotá, Colombia; 'Faculty of Medicine, \\ Pontificia Universidad Javeriana, Bogotá, Colombia
}

\section{Keywords}

Epigenetic · Genetic · Gonadotropin-releasing hormone $(\mathrm{GnRH}) \cdot$ Hypothalamic-pituitary-gonadal axis (HPG) ·

KISS1 - Puberty

\section{Abstract}

Puberty is a complex transitional phase in which reproductive capacity is achieved. There is a very wide variation in the age range of the onset of puberty, which follows a familial, ethnic, and sex pattern. The hypothalamic-pituitary-gonadal axis and several genetic, environmental, and nutritional factors play an important role in the onset of and throughout puberty. Recently, there has been significant progress in identifying factors that affect normal pubertal timing. Different studies have identified single nucleotide polymorphisms (SNPs) that affect pubertal timing in both sexes and across ethnic groups. Single genes are implicated in both precocious and delayed puberty, and epigenetic mechanisms have been suggested to affect the development and function of the $\mathrm{GnRH}$ neuronal network and responsiveness of end organs. All these factors can influence normal puberty timing, precocious puberty, and delayed puberty. The objec-

karger@karger.com www.karger.com/sxd

Karger $\stackrel{\text { ' }}{=}$
(C) 2021 The Author(s)

Published by S. Karger AG, Basel

This article is licensed under the Creative Commons Attribution 4.0 International License (CC BY) (http://www.karger.com/Services/ OpenAccessLicense). Usage, derivative works and distribution are permitted provided that proper credit is given to the author and the original publisher. tive of this review is to describe recent findings related to the genetic and epigenetic control of puberty and highlight the need to deepen the knowledge of the regulatory mechanisms of this process in the normal and abnormal context.

(C) 2021 The Author(s)

Published by S. Karger AG, Basel

\section{Introduction}

Puberty is an important period of growth and psychological and physical development in which reproductive capacity is achieved [Temboury Molina, 2009; Zhu et al., 2018]. It begins with the appearance of secondary sexual characteristics. This is followed by a sequence of maturation changes resulting from increased production of gonadal sexual steroids in response to increased secretion of gonadotropins (LH: luteinizing hormone and FSH: follicle-stimulating hormone) by the anterior pituitary gland [Mustanski et al., 2004]. There is a very wide variation in the age range of the onset of puberty, which follows a familial, ethnic, and sex pattern [Temboury Molina, 2009]. Although the factors that explain individual differences in pubertal timing have not been fully identified, evidence 


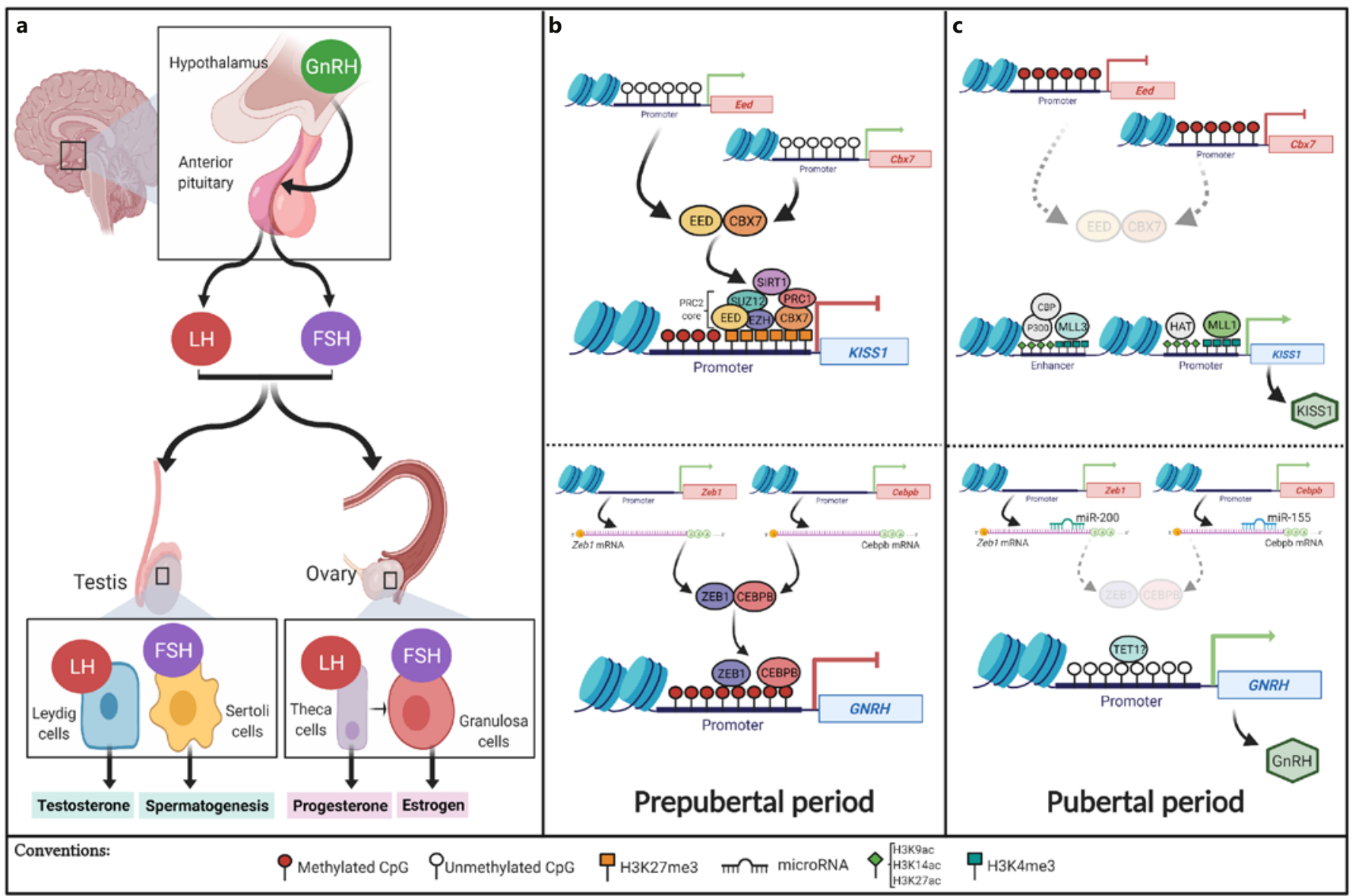

Fig. 1. Epigenetic control of the HPG axis during pubertal development. a Schematic representation of the HPG axis. The main organs and hormones involved and their role in pubertal development are shown. b Epigenetic control of genes of the HPG axis that mediate their repression in the prepubertal period are summarized and schematized. c Activation of these genes during the subsequent pubertal period (created in Biorender).

shows that the GnRH neuronal network acts under genetic control and environmental influence [Mustanski et al., 2004; Temboury Molina, 2009]. In this regard, it is proposed that there is a change in the gene expression of activators and inhibitors of puberty during the pubertal transition where the epigenetic machinery controls this genetic balance [Toro et al., 2018]. The purpose of this review is to describe recent findings related to the genetic and epigenetic control of puberty.

\section{The Hypothalamic-Pituitary-Gonadal Axis}

To attain sexual competence, all mammalian species go through puberty, a maturational period during which body growth and development of secondary sexual characteristics occur. Control of reproductive functions in humans requires temporal regulation from the hypothalamic-pituitary-gonadal (HPG) axis [Ojeda and Terasawa, 2002; López, 2012; Aylwin et al., 2019a].

This hormonal axis plays a major role during puberty, which begins with the diurnal and pulsatile secretion of gonadotropin-releasing hormone $(\mathrm{GnRH})$ for a prolonged period. This release occurs in response to excitatory impulses mainly from the secretory neurons of the hypothalamic arcuate nucleus [Jones and Lopez, 2013; Lomniczi et al., 2015]. In response to $\mathrm{GnRH}$, the anterior pituitary stimulates an increase in the pulsatile release of $\mathrm{LH}$, which is initially released nocturnally, and FSH. The latter, in turn, induces the synthesis of steroid hormones in the gonad (Fig. 1a).

In the male gonad, LH acts directly on Leydig cells, inducing the synthesis of testosterone from cholesterol. On the other hand, FSH induces the initiation of spermato- 
genesis in Sertoli cells. In the female gonad, LH stimulates the production of progesterone in theca cells, while FSH induces an increase in estrogen synthesis from granulosa cells (Fig. 1a) [López, 2012]. The increase in these steroid hormones in the gonad is responsible for the correct development of primary and secondary sexual characteristics [López, 2012; Lomniczi et al., 2015].

Although the pubertal process is known to have a strong genetic component, in recent years, epigenetics has been implicated as a significant regulatory mechanism that controls $\mathrm{GnRH}$ release. In this way, the expression of $\mathrm{GnRH}$ is repressed for the first time before puberty and is activated later; this produces an increase in the secretion of gonadotropins, which coincides with the beginning of the pubertal process [Ojeda and Terasawa, 2002; Aylwin et al., 2019b].

\section{Genetic Control of Normal Pubertal Development}

Pubertal development is estimated to be $50-75 \%$ heritable [Grotzinger et al., 2018; Zhu et al., 2018]. There is evidence of a positive correlation between the onset of puberty, the pubertal stage, and the levels of testosterone, DHEA (dehydroepiandrosterone), and progesterone among monozygotic and dizygotic twins, which supports the theory of genetic control in pubertal development [Grotzinger et al., 2018]. Furthermore, in recent years, epigenetics has been recognized as a regulatory mechanism that controls GnRH release before puberty and then modulates the increase in GnRH secretion to initiate the pubertal process [Toro et al., 2018].

During the prepubertal period, the secretory activity of $\mathrm{GnRH}$ neurons is predominately under inhibitory control, and for the onset of puberty, the central restriction must be lost. It is generally accepted that a decrease in inhibitory signals, along with an increase in excitatory neurotransmission, is required to initiate the pubertal process. Recent evidence shows that this intercellular mechanism of excitatory/inhibitory balance is a reflex of gene expression [Lomniczi et al., 2015; Toro et al., 2018]. In this regard, 3 groups of genes have been proposed: (1) puberty inhibitor (PI) genes: GAD67, PDYN, and $G n I H$; (2) puberty-activating (PA) genes: GnRH, GLS, KISS1, and TTF1; and (3) genes with a dual effect, according to the hormonal environment and cell identity: TAC3 and EAP1 [Toro et al., 2018].

Evidence for pubertal control of most of the genes mentioned above comes from animal models and/or the construction of gene coexpression networks with the help of bioinformatics tools [Toro et al., 2018]. Of this group of genes, the KISS1 gene should be highlighted. This gene encodes kisspeptin, which binds to the KISSR receptor on GnRH neurons to activate the pulsatile secretion of GnRH and promote the onset of puberty [Lomniczi et al., 2015]. The expression of KISS1 occurs in 2 main populations of neurons: kisspeptin neurons and kisspeptin/neurokinin $\mathrm{B} /$ dynophin (KNDy) neurons. Positive regulation of KISS1 expression in KNDy neurons is mediated by the binding of sex steroids to their receptors ER $\alpha$ and PR. The other way is by binding of neurokinin $B$ and dynorphin to neurokinin $\mathrm{B}$ receptor and kappa-opioid peptide receptor [Skorupskaite et al., 2014; Livadas and Chrousos, 2016; Marques et al., 2018; Yeo and Colledge, 2018]. This ensures the expression of KISS1 for proper pubertal development.

\section{Epigenetic Control of Puberty}

Although puberty has a strong genetic determination, the establishment of puberty is highly sensitive to endogenous and exogenous signals dependent on environmental factors, such as diet, nutritional status, exposure to endocrine disruptors, stress, and arduous physical training, that can affect the functionality of the HPG axis with consequences on reproductive capacity [Motti and Meccariello, 2019]. It is known that states of malnutrition, such as undernutrition and overnutrition, are causes of delayed and precocious puberty, respectively. It is now recognized that puberty is finely controlled by epigenetic mechanisms [Vazquez et al., 2018]. Epigenetics is the science that studies heritable changes in gene expression without altering the DNA sequence. Currently, 5 epigenetic mechanisms are recognized: DNA methylation, covalent histone modification ( $\mathrm{CHM})$, histone variants, chromatin remodeling complexes, and noncoding RNAs [Bártová et al., 2008; Kim et al., 2009; Toro et al., 2018]. Through epigenetic regulation, all genes in an organism are expressed in an orderly fashion at a specific time and in a specific tissue, including those involved in the proper functioning of the HPG axis [Lomniczi et al., 2015].

During the prepubertal period, in the hypothalamus, the expression of puberty-activating genes is repressed. Such is the case with the KISS1 gene that encodes kisspeptin, which is a major actor in the HPG axis that initiates puberty through GnRH release. The expression of the KISS1 gene is repressed by methylation in the CpG islands of its promoter region and the addition of $\mathrm{H} 3 \mathrm{~K}-$ $27 \mathrm{me} 3$, which is a repressive histone mark, and this is 
Table 1. Enzymes involved in the epigenetic control of pubertal development

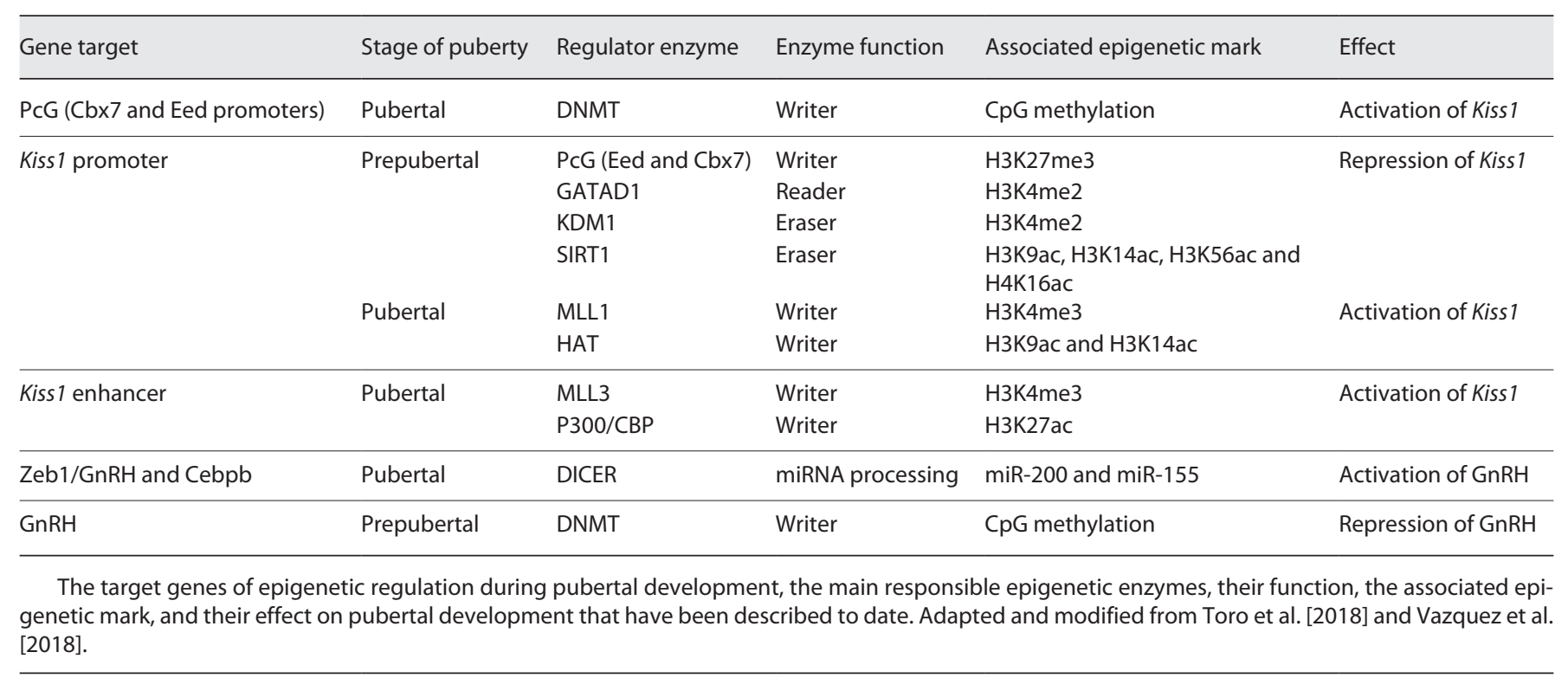

catalyzed by the enzymes of the Polycomb group (PcG): EED (Embryonic Ectoderm Development) and CBX7 (Chromobox protein homolog 7) [Kouzarides, 2007; Lomniczi et al., 2013; Toro et al., 2018]. Also interacting with PcG proteins is the SIRT1 (Sirtuin Type 1) enzyme, which removes histone acetylation, thus reinforcing the repressor effect on KISS1 [Vazquez et al., 2018]. Additionally, the expression of KISS1 is repressed by the action of the GATAD1 and KDM1 (histone demethylase) enzymes, which identify and remove the activating H3K4me2 mark, respectively [Toro et al., 2018; Motti and Meccariello, 2019]. Moreover, the binding of the transcriptional repressors Zeb1 and Cebpb has been evidenced in a murine model (Fig. 1b) [Toro et al., 2018].

For the transition to puberty, the genes that activate this process must change their regulatory regions to a state of activation. For KISS1, the event starts with the eviction of the repressor enzymes EED, CBX7, and SIRT1 from the KISS1 promoter, and then, there is a progressive enrichment of the activator mark H3K4me3 mediated by the concomitant recruitment of MLL1 and MLL3 (mixed lineage leukemia). Other activating enzymes, such as HAT and P300/CBP, are also involved in this activation process, and they catalyze the addition of acetylations, such as $\mathrm{H} 3 \mathrm{~K} 9 \mathrm{ac}, \mathrm{H} 3 \mathrm{~K} 14 \mathrm{ac}$, and $\mathrm{H} 3 \mathrm{~K} 27 \mathrm{ac}$, in both the promoter and enhancer region of KISS1 to facilitate their expression (Table 1) [Lomniczi et al., 2013; Toro et al., 2018]. As the pubertal period approaches, there is a DNA demethylation process in the GNRH promoter, thus facilitating its expression (Fig. 1c) [Kurian et al., 2010; Livadas and Chrousos, 2019]. It is believed that this demethylation is mediated by Tet enzymes because they are overexpressed during neuronal maturation, and there is evidence in murine models that indicates that the absence of Tet1 results in deficits in reproductive capacity [Kurian et al., 2010; Kurian and Terasawa, 2013].

Positive regulation of GNRH transcription by a network of miRNAs has also been observed. In a murine model, it has been shown that the microRNAs miR-200 and miR-155 regulate Gnrh1 expression through posttranscriptional control of Zeb-1 and Cebpb expression, which in turn act as transcriptional repressors of Gnrh1 (Fig. 1c) [Messina et al., 2016]. Another miRNA with a potential effect on puberty is miR-7a2, which is believed to be essential for normal murine pituitary development and HPG axis function; its deletion in mice leads to hypogonadotropic infertility [Howard and Dunkel, 2018; Toro et al., 2018].

The enzymes of PcG and TrxG groups are critical regulators of many developmental genes. They act in an antagonistic way since the proteins of the PcG group catalyze repression by adding the repressor marks $\mathrm{H} 3 \mathrm{~K} 27 \mathrm{Me} 3$ and H2AK119Ub. On the other hand, the proteins of the TrxG group activate gene expression by adding the activating marks $\mathrm{H} 3 \mathrm{~K} 4 \mathrm{Me}, \mathrm{H} 3 \mathrm{~K} 4 \mathrm{Me} 2$, and $\mathrm{H} 3 \mathrm{~K} 4 \mathrm{Me} 3$ to the regulatory regions of the gene [Schuettengruber et al., 2007; Lomniczi et al., 2015]. The removal of the EED and 
CBX enzymes of the PcG family at the beginning of pubertal development is a consequence of the methylation of their promoters and the decrease in the gene expression of these enzymes, a phenomenon that precedes pubertal development (Fig. 1c) [Lomniczi et al., 2013; Aylwin et al., 2019a; Livadas and Chrousos, 2019]. Additionally, it has been observed that the elimination of the EED and SIRT1 repressor enzymes from the KISS1 promoter for the onset of puberty is accelerated or delayed depending on the nutritional status, causing early or delayed puberty [Lomniczi et al., 2013].

Just as GNRH and KISS1 genes have a key role in the regulation of pubertal development, undoubtedly, the genes encoding their receptors, downstream genes of the HPG axis, such as $L H B, F S H B$, and those involved in steroidogenesis in the gonad are potential targets for epigenetic regulation. However, to date, the epigenetic regulation of these genes at puberty has not been characterized. Furthermore, it has been shown that the FSH receptor (FSHR) and the genes CYP11A1, HSD3B1, CYP17A1, and CYP19A1 are involved in steroidogenesis and are susceptible to control by DNA methylation [Zhang and Ho, 2011].

\section{Genetics of Normal Female Puberty}

Puberty is considered normal when it begins between the ages of 8 and 13 in females [Abreu and Kaiser, 2016], with the appearance of the breast bud being the first sign of the onset of puberty. To explain what contributes to the onset of puberty at a molecular level, Hagen et al. [2014] evaluated the effect of 3 polymorphisms that influence the action of FSH on the age at thelarche in a cohort of 964 healthy girls. In this study, girls homozygous for the FSHR-29AA (c.-29G >A) variant, located in the gene-promoting region, were found to enter puberty 7.4 (2.5-12.4) months later than carriers of the common FSHR-29 GG+GA variants $(p=0.003)$. It seems that the FSHR c. $-29 \mathrm{G}>$ A variant reduces the expression of the FSHR receptor [Hagen et al., 2014]. Additionally, it was reported that the FSHB -211TT (c.-211G>T) variant, which is located in the promoter of the gene encoding the FSH $\beta$ subunit, produces a decrease in FSH production due to an alteration in the affinity of the LHX3 transcription factor for the FSHB gene promoter [Benson et al., 2013]. This occurs when it is present in a homozygous state, and compared to carriers of the FSHB-211GG and GT variants, it facilitates a later onset of puberty, although it is not statistically significant. However, it has an additive effect in increasing the age of puberty onset up to $1.9(0.2-3.6)$ months when found concomitantly with the FSHR c. $-29 \mathrm{G}>\mathrm{A}$ variant [Benson et al., 2013].

Moreover, variants in the LIN28B gene, a powerful and specific regulator of microRNA processing [Ong et al., 2009], have also been involved in modifying the timing of thelarche. The LIN28B variant g.105378954C >T (rs7759938) in the homozygous state was associated with the onset of thelarche 8.06 months later compared to carriers of the common variant, whose effect was independent of the variants described above [Busch et al., 2018]. Furthermore, there is evidence that rs7759938 in the homozygous state is associated with the onset of menarche 6.02 months later compared to carriers of the common variant [Busch et al., 2018]. In another large genomewide association (GWA) study, it was observed that the LIN28B rs314276 polymorphism was associated with an earlier mean age at menarche by 0.22 years $(95 \% \mathrm{CI}=$ 0.14-0.29) [Ong et al., 2009].

Another variant of interest for its effect on the action of FSH is the FSHR variant c.2039A $>$ G; pN680S, which is located in the gene region encoding the intracellular domain of the FSH receptor. It has been observed that homozygous carriers of this variant need more exogenous FSH for sufficient ovarian stimulation compared to homozygous carriers for the FSHR 2039AA variant or composite heterozygous FSHR 2039AG [Perez Mayorga et al., 2000]. Although this variant does not appear to influence puberty onset [Hagen et al., 2014], carriers of the FSHR 2039GG genotype have been observed to have significantly smaller glandular breast tissue and lower serum estradiol concentrations [Ong et al., 2009; Henriksen et al., 2016; Busch et al., 2018].

It is also important to point out that the beginning of puberty is a highly polygenic process and that rare variants near the MKRN3 and DLK1 genes, when inherited by the paternal line, have been associated with early puberty and precocious puberty [Perry et al., 2014; Pagani et al., 2020]. The association of these genes with precocious puberty is detailed in the section on the genetics of precocious puberty.

\section{Genetics of Normal Male Puberty}

Puberty in males is considered normal when it begins between 9 and 14 years of age [Abreu and Kaiser, 2016]. The onset and progression of puberty in boys are manifested by gradual enlargement of the external genitalia, initially of the testicular volume, and the extension of 
the pubic hair. By convention, these characteristics are classified into 5 stages of sexual maturation. However, it is difficult to assess these stages accurately in retrospective epidemiological studies. Voice change represents a distinctive event that usually occurs abruptly at the end of puberty and is taken as a marker of pubertal development [Ong et al., 2009; Day et al., 2015]. It has been observed that the LIN28B rs 314276 polymorphism is associated with a voice change at the age of 15 , an advanced stage of pubic hair at the age of 13 (described as Tanner 5 ), and an accelerated growth rate at age 10 [Ong et al., 2009].

\section{Genetics of Precocious Puberty}

Precocious puberty is defined clinically by the development of secondary sexual characteristics before the age of 8 years in girls and 9 years in boys [Yi et al., 2018]. It is associated with a low final height, compared to their genetic potential for height, and an increased risk of developing psychological problems [Wojniusz et al., 2016; Yi et al., 2018], which may be gonadotropin-dependent or gonadotropin-independent [Teles et al., 2008].

\section{Gonadotropin-Dependent Precocious Puberty or}

Central Precocious Puberty

Central precocious puberty (CPP) is caused by the early maturation of the HPG axis [Abreu and Kaiser, 2016]. In 2008, the first monogenic cause of CPP was identified in a patient with a heterozygous gain-of-function mutation in the KISS1R gene, which codes for the kisspeptin receptor [Teles et al., 2008; Canton et al., 2019]. In 2010, a mutation in the KISS1 gene was described in a child who developed CPP at 1 year of age [Silveira et al., 2010]. Recently, pathogenic variants in the MKRN3 gene have been associated with cases of familial and nonfamilial CPP [Abreu et al., 2013; Schreiner et al., 2014; Yi et al., 2018]. MKRN3 plays a role in protein ubiquitination and can act by inhibiting factors that stimulate pulsatile pubertal GnRH release [Schreiner et al., 2014]. Mutations causing loss of MKRN3 function are claimed to represent the most common genetic cause of nonsyndromic CPP [ Valadares et al., 2019]. Recently, mutations causing loss of function in the DLK1 gene have been described in women with a history of precocious puberty and metabolic disorders, such as overweight/obesity, glucose intolerance/ type 2 diabetes mellitus, and hyperlipidemia [Dauber et al., 2017; Canton et al., 2019; Gomes et al., 2019] (Table 2).
On the other hand, CPP is part of the phenotypic spectrum of some chromosome diseases, including Temple syndrome (associated with the involvement of the chromosomal region susceptible to imprinting and involving the DLK1 gene), Silver-Russell syndrome, and WilliamsBeuren syndrome [Macedo et al., 2016; Canton et al., 2019]. Additionally, there are some polymorphic variants in the GNRH1, LHB, FSHB, TTF1, EAP1, NPVF, and NPFFR1 genes (which are biologically linked to gonadotropin signaling) and the CYP19A1, CYP1A1, CYP1, and $C Y P 1 B 1$ genes (genes encoding steroidogenesis enzymes) with possible associations with precocious puberty. However, the small size of the studies excludes any definitive conclusions [Zhu et al., 2018]. In addition, some variants in copy numbers, such as 1p36 deletion, 9p distal deletion, 9q34.3 duplication (which includes the NOTCH gene), Xp11.23p11.22 duplication, and CDKL5 gene deletion, have been associated with idiopathic CPP [Canton et al., 2019] (Table 2).

\section{Gonadotropin-Independent Precocious Puberty or Peripheral Precocious Puberty}

Genetic causes of autonomic gonadal activation have been widely described, such as testotoxicosis and McCune-Albright syndrome (MAS) [Macedo et al., 2016] (Table 2).

Testotoxicosis, or familial precocious puberty limited to the male, is caused by germline mutations with constitutive activation of the LHCGR gene, which encodes the luteinizing hormone receptor/choriogonadotropin receptor located on chromosome $2 \mathrm{p} 21$. The inheritance pattern is autosomal dominant. Pituitary LH and placental human chorionic gonadotropin bind with high affinity to LHCGR. Activating mutations in LHCGR lead to increased production of cAMP and testosterone in the absence of LH. Family members with the same mutation may present phenotypes of variable severity, suggesting variable expression of the disease [Macedo et al., 2016] (Table 2).

MAS is caused by postzygotic somatic activating mutations in the GNAS gene, which encodes the a subunit of the guanine nucleotide-binding protein (Gsa) that stimulates adenylate cyclase and leads to the generation of cAMP. Clinically, this disorder is characterized by a classic triad of café-au-lait skin pigmentation areas, polyostotic fibrous dysplasia, and peripheral precocious puberty. The clinical presentation is heterogeneous and may include other hyperfunctional endocrinopathies [Macedo et al., 2016] (Table 2).
Manotas/González/Céspedes/Forero/ Rojas Moreno 
Table 2. Genetic causes of puberty disorders

\begin{tabular}{|c|c|}
\hline Category & Genetic causes \\
\hline \multicolumn{2}{|l|}{ Precocious puberty } \\
\hline Central precocious puberty & $\begin{array}{l}\text { Monogenic causes: } \\
\text { (1) Gain-of-function (activating) mutations in KISS1R and KISS1 genes (kisspeptin pathway genes) } \\
\text { (2) Loss-of-function (inactivating) mutations in MKRN3 gene } \\
\text { (3) Loss-of-function (inactivating) mutations in DLK1 gene } \\
\text { Chromosomal abnormalities: } \\
\text { (1) } 1 \text { p36 deletion } \\
\text { (2) } 9 p \text { distal deletion } \\
\text { (3) } 9 \text { q34.3 duplication (which includes the NOTCH gene) } \\
\text { (4) Xp11.23-p11.22 duplication }\end{array}$ \\
\hline Peripheral precocious puberty & $\begin{array}{l}\text { (1) Testotoxicosis: constitutive activation germline mutations in the LHCGR gene } \\
\text { (2) McCune Albright syndrome: postzygous somatic activating mutations in GNAS }\end{array}$ \\
\hline \multicolumn{2}{|l|}{ Genetics of delayed puberty } \\
\hline Constitutional delay of growth and puberty & Genetic background is unknown. Probably pathogenic variants in the IGSF10 gene have been associated \\
\hline Kallmann syndrome & $\begin{array}{l}\text { Mutated genes: KAL1, FGFR1, FGF8, FGF17, IL17RD,DUSP6, SPRY4,FLRT3,KLB,HS6ST1, CHD7, WDR11, SEMA3A, } \\
\text { SEMA3E, IGSF10, SMCHD1, CCDC141, FEZF1, SOX10, PROKR2, PROK2 }\end{array}$ \\
\hline $\begin{array}{l}\text { Normosmic idiopathic hypogonadotropic } \\
\text { hypogonadism }\end{array}$ & $\begin{array}{l}\text { Mutated genes: CHD7, DAX1, FGF8, FGF17, FGFR1, HS6ST1, NSMF, LEP, LEPR, PROK2, PROKR2, WDR11, GNRH1, } \\
\text { GNRHR, KISS1, KISS1R, SRA1, TAC3, TACR3 }\end{array}$ \\
\hline Hypogonadism hypergonadotropic & $\begin{array}{l}\text { Monogenic causes: } \\
\text { (1) Enzymatic defects in testosterone biosynthesis: 17a-hydroxylase, } 3 \beta \text {-hydroxysteroid dehydrogenase, } \\
\text { 17, } 20 \text {-lyase and } 17 \beta \text {-hydroxysteroid dehydrogenase deficiency } \\
\text { (2) Inactivating mutations in the gonadotropin receptor genes } \\
\text { (3) Polymalformative syndromes } \\
\text { Chromosomal abnormalities: } \\
\text { (1) Turner syndrome } \\
\text { (2) Klinefelter syndrome }\end{array}$ \\
\hline
\end{tabular}

\section{Genetics of Delayed Puberty}

Delayed puberty is clinically defined by the absence or incomplete development of secondary sexual characteristics after age 13 in girls or after age 14 in boys [Abreu and Kaiser, 2016; Raivio and Miettinen, 2019]. Delayed puberty may be a variant of normal development, known as constitutional delay of growth and puberty, where the onset of puberty is delayed but occurs spontaneously before age 18. In contrast, hypogonadism is characterized by the absence or incomplete development of secondary sexual characteristics at age 18 in both sexes. Hypogonadism can be hypogonadotropic or hypergonadotropic [Abreu and Kaiser, 2016; Zhu et al., 2018] (Table 2).

\section{Constitutional Delay of Growth and Puberty}

Constitutional delay of growth and puberty (CDGP) is predominantly segregated in an autosomal dominant pattern of inheritance. However, its genetic background is unknown. Potentially pathogenic variants in the IGSF10 gene have been associated with CDGP [Howard et al.,
2016]. Studies in mouse and zebrafish models suggest that IGSF10 is required for proper migration of $\mathrm{GnRH}$ neurons [Howard et al., 2016]. Rare variants have also been associated with the GHSR gene (which encodes the ghrelin receptor) and the LEP gene (which encodes leptin). However, it is not clear whether these variants are more common in individuals with delayed puberty than in the general population [Zhu et al., 2018] (Table 2).

\section{Hypogonadotropic Hypogonadism}

This disorder can be caused by a deficiency in GnRH secretion or action or both, and it can be classified as idiopathic or secondary. Idiopathic hypogonadotropic hypogonadism (IHH) is divided into 2 major categories: Kallmann syndrome (KS) and normosmic IHH (nIHH). Inactivating variants in more than 50 genes have been reported to cause IHH. These genetic defects have been identified in approximately $40-50 \%$ of cases [Abreu and Kaiser, 2016; Topaloğlu, 2017].

KS is associated with anosmia or isolated hypogonadotropic hypogonadism when the sense of smell is not 
compromised [Abreu and Kaiser, 2016]. It is caused by a defect in the development of the olfactory system and by embryonic migration interruption of $\mathrm{GnRH}$-synthesizing neurons from the olfactory epithelium to the hypothalamic region of the brain. Most known cases are sporadic, but familial forms have been described. Some causative genes include KAL1 in the X-linked form; FGFR, FGF8, CHD7, and SOX10 in the AD form; and $P R O K R 2$ and $P R O K 2$ in the AR form [Balasubramanian and Crowley, 2017]. Normosmic IHH results from dysfunction of normally placed GnRH neurons in the hypothalamus. These cases typically do not have any accompanying congenital lesions, and pathogenic variants in the CHD7, FGF8, FGF17, FGFR1, HS6ST1, NSMF, PROK2, PROKR2, WDR11, GNRH1, GNRHR, KISS1, KISS1R, TAC3, and TACR3 genes have been described to cause nIHH [Balasubramanian and Crowley, 2017] (Table 2).

\section{Hypergonadotropic Hypogonadism}

Gonadal failure is a relatively common cause of delayed puberty in girls (21\%), but it is rarely found in boys (4\%). Regarding hypergonadotropic hypogonadism in girls, approximately one-quarter of cases are attributed to Turner syndrome [Raivio and Miettinen, 2019]; other causes include pure gonadal dysgenesis and loss-of-function mutations in the genes encoding gonadotropin receptors [Mayáyo et al., 2010]. Klinefelter syndrome is the most common cause of male hypogonadotropic hypogonadism. Similarly, enzymatic defects in testosterone biosynthesis, such as $17 \alpha$-hydroxylase, $3 \beta$-hydroxysteroid dehydrogenase, 17,20-lyase, and 17 $\beta$-hydroxysteroid dehydrogenase deficiencies, and inactivating mutations in gonadotropin receptor genes have also been associated with hypergonadotropic hypogonadism in boys [Mayáyo et al., 2010]. It should be noted that several polymalformative syndromes are accompanied by hypogonadotropic hypogonadism. Among these, Noonan syndrome stands out as one of the main syndromes associated with hypogonadotropic hypogonadism in both girls and boys [Mayáyo et al., 2010] (Table 2).

\section{Conclusion}

Puberty is a period of growth and psychological and physical development in which reproductive capacity is achieved. It begins with the appearance of secondary sexual characteristics followed by a sequence of changes. The changes result from the increased production of gonadal sex steroids in response to increased secretion of gonadotropins by the anterior pituitary gland, which is driven by the hypothalamic release of GnRH. In this process, the GnRH neuronal network acts under genetic and epigenetic control and environmental influence. The beginning of puberty is a highly polygenic process. In this regard, 3 groups of genes have been proposed: puberty inhibitor genes, puberty-activating genes, and genes with a dual effect. Of this group of genes, KISS1 gene encodes kisspeptin, which is a major actor in the HPG axis that initiates puberty through $\mathrm{GnRH}$ release. The expression of the KISS1 gene is repressed by methylation in the CpG islands of its promoter region, and this is catalyzed by the enzymes of the Polycomb group and the action of the GATAD1 and KDM1 enzymes. GNRH also have a key role in the regulation of pubertal development. Undoubtedly, the genes encoding their receptors, downstream genes of the HPG axis, such as $L H B, F S H B$, and those involved in steroidogenesis in the gonad are potential targets for epigenetic regulation. However, to date, the epigenetic regulation of these genes at puberty has not been characterized.

Rare variants in MKRN3, DLK1, KISS1, and KISS1R genes represent the known genetic causes of CPP. There are some polymorphic variants in the genes with are biologically linked to gonadotropin and genes encoding steroidogenesis enzymes with possible associations with precocious puberty. In addition, some variants in copy numbers have been also associated, however, the small size of the studies excludes any definitive conclusions.

CDGP is predominantly segregated in an autosomal dominant pattern of inheritance, however, its genetic background is unknown. Potential pathogenic variants in the IGSF10 gene and variants in GSHR and LEP genes have been associated, however, it is not clear whether these variants are more common in individuals with delayed puberty than in the general population. In relation to delayed puberty associated to hypogonadotropic hypogonadism, the genetic defects have been identified in approximately $40-50 \%$ of cases. On the other hand, gonadal failure is a relatively common cause of delayed puberty in girls, but it is rarely found in boys.

The timing and progression of puberty depend on the strict control of the genetic and epigenetic machinery and different internal and external environmental stimuli. Undoubtedly, there is much to discover and understand about the signaling pathways triggered by genetic and epigenetic mechanisms responsible for prepubertal neuroendocrine development. 


\section{Conflict of Interest Statement}

The authors have no conflicts of interest to declare.

\section{Funding Sources}

The preparation of the manuscript was funded by Hospital Universitario San Ignacio, Pontificia Universidad Javeriana.

\section{Author Contributions}

M.C.M., D.G., C.C., and A.R. designed the principal items of the manuscript. M.C.M., D.G. developed and wrote the main parts of the manuscript. C.F., C.C., and A.R. provided academic concepts in the manuscript.

\section{References}

Abreu AP, Dauber A, Macedo DB, Noel SD, Brito VN, Gill JC, et al. Central precocious puberty caused by mutations in the imprinted gene MKRN3. N Engl J Med. 2013;368:2467-75.

Abreu AP, Kaiser UB. Pubertal development and regulation. Lancet Diabetes Endocrinol. 2016; 4:254-64.

Aylwin CF, Toro CA, Shirtcliff E, Lomniczi A. Emerging genetic and epigenetic mechanisms underlying pubertal maturation in adolescence. J Res Adolesc. 2019a;29:54-79.

Aylwin CF, Vigh-Conrad K, Lomniczi A. The emerging role of chromatin remodeling factors in female pubertal development. Neuroendocrinology. 2019b;109:208-17.

Balasubramanian R, Crowley WF. Isolated gonadotropin-releasing hormone ( $\mathrm{GnRH})$ deficiency. In: Adam MP, Ardinger HH, Pagon RA, editors. GeneReviews ${ }^{\oplus}$ [Internet]. Seattle: University of Washington; 2017.

Bártová E, Krejcí J, Harnicarová A, Galiová G, Kozubek S. Histone modifications and nuclear architecture: A review. J Histochem Cytochem. 2008;56:711-21.

Benson CA, Kurz TL, Thackray VG. A human FSHB promoter SNP associated with low FSH levels in men impairs LHX3 binding and basal FSHB transcription. Endocrinology. 2013; 154:3016-21.

Busch AS, Hagen CP, Assens M, Main KM, Almstrup K, Juul A. Differential impact of genetic loci on age at thelarche and menarche in healthy girls. J Clin Endocrinol Metab. 2018;103:228.

Canton APM, Seraphim CE, Brito VN, Latronico AC. Pioneering studies on monogenic central precocious puberty. Arch Endocrinol Metab. 2019;63:438-44.

Dauber A, Cunha-Silva M, MacEdo DB, Brito VN, Abreu AP, Roberts SA, et al. Paternally inherited DLK1 deletion associated with familial central precocious puberty. J Clin Endocrinol Metab. 2017;102:1557-67.

Day FR, Bulik-Sullivan B, Hinds DA, Finucane HK, Murabito JM, Tung JY, et al. Shared genetic aetiology of puberty timing between sexes and with health-related outcomes. Nat Commun. 2015;6:8842.

Gomes LG, Cunha-Silva M, Crespo RP, Ramos CO, Montenegro LR, Canton A, et al. Dlk1 is a novel link between reproduction and metabolism. J Clin Endocrinol Metab. 2019;104: 2112.
Grotzinger AD, Briley DA, Engelhardt LE, Mann FD, Patterson MW, Tackett JL, et al. Genetic and environmental influences on pubertal hormones in human hair across development. Psychoneuroendocrinology. 2018;90: 76-84.

Hagen CP, Sørensen K, Aksglaede L, Mouritsen A, Mieritz MG, Tinggaard J, et al. Pubertal onset in girls is strongly influenced by genetic variation affecting FSH action. Sci Rep. 2014; 4:6412-6.

Henriksen LS, Hagen CP, Assens M, Busch AS, Skakkebæk NE, Almstrup K, et al. Genetic variations in $\mathrm{FSH}$ action affect sex hormone levels and breast tissue size in infant girls: A pilot study. J Clin Endocrinol Metab. 2016; 101:3191-8.

Howard SR, Dunkel L. The genetic basis of delayed puberty. Neuroendocrinology. 2018; 106:283.

Howard SR, Guasti L, Ruiz-Babot G, Mancini A, David A, Storr HL, et al. IGSF10 mutations dysregulate gonadotropin-releasing hormone neuronal migration resulting in delayed puberty. EMBO Mol Med. 2016;8:62642.

Jones RE, Lopez KH. Human Reproductive Biology [Internet] Elsevier Science; 2013. Available from: https://books.google.com.co/ books?id=M4kEdSnS-pkC.

Kim JK, Samaranayake M, Pradhan S. Epigenetic mechanisms in mammals. Cell Mol Life Sci. 2009;66:596-612.

Kouzarides T. Chromatin modifications and their function. Cell. 2007;128(4):693-705.

Kurian JR, Keen KL, Terasawa E. Epigenetic changes coincide with in vitro primate $\mathrm{GnRH}$ neuronal maturation. Endocrinology. 2010; 151:5359-68.

Kurian JR, Terasawa E. Epigenetic control of gonadotropin releasing hormone neurons. Front Endocrinol (Lausanne). 2013;4:61.

Livadas S, Chrousos GP. Control of the onset of puberty. Curr Opin Pediatr. 2016;28:551-8.

Livadas S, Chrousos GP. Molecular and environmental mechanisms regulating puberty initiation: An integrated approach. Front Endocrinol (Lausanne). 2019;10:828.

Lomniczi A, Loche A, Castellano JM, Ronnekleiv OK, Bosch M, Kaidar G, et al. Epigenetic control of female puberty. Nat Neurosci. 2013;16: 281-9.
Lomniczi A, Wright H, Ojeda SR. Epigenetic regulation of female puberty. Front Neuroendocrinol. 2015;36:90-107.

López M. Regulación neurológica y hormonal de la función reproductora. Fisiología de la pubertad y del climaterio [Internet]. 2012;15.

Macedo DB, Silveira LF, Bessa DS, Brito VN, Latronico AC, Bulcão D, et al. Sexual precocity-genetic bases of central precocious puberty and autonomous gonadal activation. Endocr Dev. 2016;29:50-71.

Marques P, Skorupskaite K, George JT, Anderson RA. Physiology of GNRH and Gonadotropin Secretion [Internet]. Endotext, South Dartmouth. 2018. Available from: https://www. ncbi.nlm.nih.gov/books/NBK279070/.

Mayáyo E, Labarta J, Sinues B, Á F. Pubertad retrasada. Hipogonadismos. In: Pombo $\mathrm{M}$, Audí L, Bueno M, Calzada R, Cassorla C, Diéguez C, et al. et al., editors. Tratado de Endocrinología Pediátrica, 4ta Edició; 2010. p. 65.

Messina A, Langlet F, Chachlaki K, Roa J, Rasika $\mathrm{S}$, Jouy N, et al. A microRNA switch regulates the rise in hypothalamic GnRH production before puberty. Nat Neurosci. 2016;19:83544.

Motti ML, Meccariello R. Minireview: The epigenetic modulation of KISS1 in reproduction and cancer. Int J Environ Res Public Health. 2019;16:1-9.

Mustanski BS, Viken RJ, Kaprio J, Pulkkinen L, Rose RJ. Genetic and environmental influences on pubertal development: Longitudinal data from Finnish twins at ages 11 and 14. Dev Psychol. 2004;40:1188-98.

Ojeda SR, Terasawa E. Neuroendocrine Regulation of Puberty. In: Pfaff DW, Arnold AP, Fahrbach SE, Etgen AM, Rubin B, Behavior RTBT - $\mathrm{H}$, editors. Hormones, Brain and Behaviour. New York: Elsevier; 2002. p. 589659.

Ong KK, Elks CE, Li S, Zhao JH, Luan J, Andersen $\mathrm{LB}$, et al. Genetic variation in LIN28B is associated with the timing of puberty. Nat Genet. 2009;41:729-33.

Pagani S, Calcaterra V, Acquafredda G, Montalbano C, Bozzola E, Ferrara P, et al. MKRN3 and KISS1R mutations in precocious and early puberty. Ital J Pediatr. 2020;46:39. 
Perez Mayorga M, Gromoll J, Behre HM, Gassner C, Nieschlag E, Simoni M. Ovarian response to follicle-stimulating hormone (FSH) stimulation depends on the FSH receptor genotype. J Clin Endocrinol Metab. 2000;85:3365-9.

Perry JR, Day F, Elks CE, Sulem P, Thompson DJ, Ferreira T, et al. Parent-of-origin-specific allelic associations among 106 genomic loci for age at menarche. Nature. 2014;514:92-7.

Raivio T, Miettinen PJ. Constitutional delay of puberty versus congenital hypogonadotropic hypogonadism: Genetics, management and updates. Best Pract Res Clin Endocrinol Metab. 2019;33:101316.

Schreiner F, Gohlke B, Hamm M, Korsch E, Woelfle J. MKRN3 mutations in familial central precocious puberty. Horm Res Paediatr. 2014;82:122-6.

Schuettengruber B, Chourrout D, Vervoort M, Leblanc B, Cavalli G. Genome regulation by polycomb and trithorax proteins. Cell. 2007; 128:735-45.

Silveira LG, Noel SD, Silveira-Neto AP, Abreu AP, Brito VN, Santos MG, et al. Mutations of the KISS1 gene in disorders of puberty. J Clin Endocrinol Metab. 2010;95:2276-80.
Skorupskaite K, George JT, Anderson RA. The kisspeptin-GnRH pathway in human reproductive health and disease. Hum Reprod Update. 2014;20:485-500.

Teles MG, Bianco SDC, Brito VN, Trarbach EB, Kuohung W, Xu S, et al. A GPR54-activating mutation in a patient with central precocious puberty. N Engl J Med. 2008;358:709-15.

Temboury Molina MC. Desarrollo puberal normal: Pubertad precoz. Rev Pediatr Aten Primaria. 2009;11:127-42.

Topaloğlu AK. Update on the genetics of idiopathic hypogonadotropic hypogonadism. J Clin Res Pediatr Endocrinol. 2017;9(Suppl 2): $113-22$.

Toro CA, Aylwin CF, Lomniczi A. Hypothalamic epigenetics driving female puberty. J Neuroendocrinol. 2018;30:e12589.

Valadares LP, Meireles CG, De Toledo IP, Santarem de Oliveira R, Gonçalves de Castro LC, Abreu AP, et al. MKRN3 Mutations in Central Precocious Puberty: A Systematic Review and Meta-Analysis. J Endocr Soc. 2019;3: 979-95.
Vazquez MJ, Toro CA, Castellano JM, Ruiz-Pino F, Roa J, Beiroa D, et al. SIRT1 mediates obesity- and nutrient-dependent perturbation of pubertal timing by epigenetically controlling Kiss1 expression. Nat Commun. 2018;9: 4194-15.

Wojniusz S, Callens N, Sütterlin S, Andersson S, De Schepper J, Gies I, et al. Cognitive, emotional, and psychosocial functioning of girls treated with pharmacological puberty blockage for idiopathic central precocious puberty. Front Psychol. 2016;7:1053.

Yeo SH, Colledge WH. The role of Kiss1 neurons as integrators of endocrine, metabolic, and environmental factors in the hypothalamicpituitary-gonadal axis. Front Endocrinol (Lausanne). 2018;9:188.

Yi BR, Kim HJ, Park HS, Cho YJ, Kim JY, Yee J, et al. Association between MKRN3 and LIN28B polymorphisms and precocious puberty. BMC Genet. 2018;19:47-7.

Zhang X, Ho SM. Epigenetics meets endocrinology. J Mol Endocrinol. 2011;46:R11

Zhu J, Kusa TO, Chan YM. Genetics of pubertal timing. Curr Opin Pediatr. 2018;30:532-40. 